Research Article

\title{
Evaluation of Effective Pharmaceutical Care Interventions in the Identification and Resolution of Drug Related Problems in A Major Trauma Care Centre.
}

\author{
Athira Thomson ${ }^{1 *}$, Mariya Thomas Chacko ${ }^{1}$, Priscilla Mary James ${ }^{1}$, Sneha Saira Jijii ${ }^{1}$, Hemalatha Selvaraj ${ }^{2}$, Britto L Duraisingh ${ }^{3}$, Sheik \\ Haja Sherief ${ }^{4}$, Thangavel Sivakumar ${ }^{5}$ \\ 1.PharmD Interns, Department of Pharmacy Practice, Nandha College of Pharmacy, Erode, Tamil Nadu, India. \\ 2.Assistant Professor, Department of Pharmacy Practice, Nandha College of Pharmacy, Erode, Tamil Nadu, India. \\ 3. Clinical Pharmacist, Ganga Medical Centre Hospital, Coimbatore, Tamil Nadu, India. \\ 4.HOD, Department of Pharmacy Practice, Nandha College of Pharmacy, Erode, Tamil Nadu, India. \\ 5. Principal, Nandha College of Pharmacy, Erode, Tamil Nadu, India. \\ *Corresponding author's E-mail: athirathomson0495@gmail.com
}

Received: 14-09-2020; Revised: 25-10-2020; Accepted: 02-11-2020; Published on: 15-11-2020.

\section{ABSTRACT}

Drug Related Problems are common in hospitalization where there are numerous changes in the dosage of the patient's medication. Pharmaceutical care is an emerging method for maximizing drug treatment, reducing drug related complications and enhancing patient quality of life. The aim of this study is to assess the impact of pharmaceutical care service in detecting and addressing Drug Related Problems in a major trauma care center. The Prospective Interventional hospital study was conducted in 1000 patients who were admitted to medical wards from February to July 2018. The clinical pharmacist has compiled and analyzed data on drug use. Drug Related problems have been identified, analyzed and documented according to PCNE (Pharmaceutical Care Network Europe) V8.02 criteria. PCNE V 8.02 formulated pharmaceutical care plans proposed interventions. 627 Drug Related Problems were identified among 1000 inpatients and interventions were made at prescriber, patient and in drug level. 345 out of 350 potential problems were prevented as a result of the interventions and 268 out of 277 actual problems were resolved. The clinical pharmacists have been involved in dose adjustment, monitoring, evaluation of drug discontinuation, drug substitution and additional therapy, patient counselling, increased dose and reference to prescriber. The evaluation and execution of pharmaceutical care services has a positive impact among the study patients in reducing Drug Related Problems. To the benefit of patients, pharmaceutical care service must be replicated to all other hospitals.

Keywords: Drug Related Problems, Pharmaceutical care Network Europe, Clinical pharmacist, Intervention, Actual Drug related problem, Potential Drug related problem, Pharmaceutical Care.

QUICK RESPONSE CODE $\rightarrow$

DOI:

10.47583/ijpsrr.2020.v65i01.008

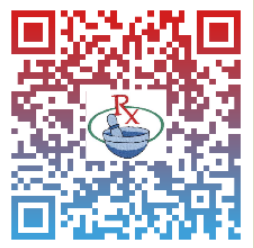

DOI link: http://dx.doi.org/10.47583/ijpsrr.2020.v65i01.008

\section{INTRODUCTION}

P

harmaceutical care is the responsible provision of drug therapy with the aim of achieving definite outcomes that improve quality of life in patients ${ }^{1}$.It involves a process where a clinical pharmacist cooperates with a patient and other health care professionals in the design, implementation and monitoring of a therapeutic plan that will produce definite outcomes for the patient. ${ }^{2}$ The main purpose of the procedure is to create, execute and track a therapeutic plan/ establish, execute and monitor the therapeutic plan ${ }^{3}$. A Drug Related Problem is defined as any incident or condition involving drug treatment that interferes or potentially interferes with the patient achieving the desired outcome of medical care. ${ }^{4}$ DRPs may contribute to decreased quality of life, increased hospital stay, overall increase health costs and even increase risk of morbidity and mortality. ${ }^{5-7}$ Clinical pharmacists can play a significant role in this. Actual DRPs are events that have already taken place in patients, whereas a potential DRP is an event that is likely to develop if clinical pharmacists do not take appropriate measures.

Implementation of pharmaceutical care services in patient care showed improvement in medication adherence to medication, with reduced prescribing errors. Providing pharmaceutical care services, a more optimal, safe, cost effective and individualized treatment can be given, thereby solving drug related problems. ${ }^{8}$

\section{MATERIALS AND METHODS}

\section{Study design and population}

For a period of 6 months from 1 February 2018 to 31 July 2018, a prospective interventional study was conducted in Ganga Medical Center, Coimbatore. The total number of patients who participated in the study was 1000 . The study included surgical in-patients, male as well as female. Pregnant women, outpatients and those with psychiatric illness were excluded. From admission to discharge all patients who met the inclusion criteria were followed during the research. The data were collected using a well-structured form of data collection that includes demographics of patients, diagnosis, problems 
with drug selection, dose related problems, possible drug interactions, adverse drug reactions and other events related to medication. The patient's case sheets were periodically checked and all the drug related problems found had been reported in the data collection method intended for this research.

DRPs were categorized using the PCNE classification $(\text { V8.02 })^{9}$ as actual and potential DRPs. This classification of PCNE was categorized into problems, causes, planned interventions, acceptance and status of DRP. Pharmaceutical care has been applied by providing information related to the drug, illness and diet. Naranjo Scale analysed and reported ADRs.

\section{Data analysis}

The data gathered have been updated in spreadsheets using Microsoft Office Excel 2013. DRPs have been identified, assessed and recorded according to the criteria PCNE (Pharmaceutical Care Network Europe) V8.02.

\section{RESULTS AND DISCUSSION}

\section{Characteristics of study population}

A total of 1000 patients from various orthopaedic departments such as trauma, plastic, spine, arthroplasty, arthroscopy in a trauma care center were analysed during the study. Out of the 1000,627 were found to have drug related problems of which $410(65.39 \%)$ and $217(34.60 \%)$ were seen in males and females respectively. Most DRPs occurred in the age group of 61-70years. Gender and age wise distribution are listed in Table 1.

Table 1: Demographic data.

\begin{tabular}{|c|c|c|}
\hline Sex & Total No. of Cases (N=627) & Percentage (\%) \\
\hline Male & 410 & 63.59 \\
\hline Female & 217 & 31.60 \\
\hline Age group & & \\
\hline $18-30$ & 122 & 19.45 \\
\hline $31-50$ & 138 & 22.00 \\
\hline $51-70$ & 260 & 41.46 \\
\hline$>70$ & 107 & 17.06 \\
\hline
\end{tabular}

\section{Incidence of Drug Related Problems}

Total occurrence of drug related problems between different departments are outlined in Figure 1. Majority of drug related problems were from the trauma section. Being a major trauma care centre, more cases with road traffic accidents, traumatic car crash injuries, gunshot wounds, major burns, serious falls etc. were admitted.

\section{INCIDENCE OF DRPS AMONG VARIOUS DEPARTMENTS}

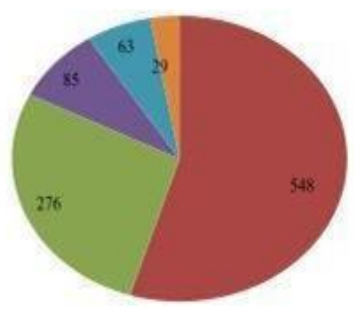

EDEPARTMENTS
=IRAIMA
MPINE
= PLASTIC
= ARTHROPLASTY
= ARTHROSCOPY

\section{Classification of Drug Related Problems}

627 drug related problems found have been listed on the basis of the PCNE V8.02 criteria which is shown in Table 2-6.

The most common type of problem among 627 DRPs was found to be unclear problems/complaints (61.4\%) which required patient counseling followed by poor treatment effectiveness (27.27\%). Due to lack of awareness among the patients $(49.76 \%)$, the majority of DRP was found to be poor compliance followed by improper drug selection $(22.56 \%)$ and dose selection (16.58\%). Interventions were performed from which $320(32 \%)$ of interventions were performed by patients, caregivers or relatives which was basically patient counselling. Acceptance rates of intervention was highest at prescriber level 610(61.0\%). Most of the problems were partially solved in the case of DRP status 320 (32.0\%).

\section{Evaluation of pharmaceutical care interventions}

627 interventions have been conducted and recorded in this report. Of those, 315 were related to drug therapy and 312 involved educational provisions. By the end of the study, $55.02 \%$ of potential DRP and $44.17 \%$ of the actual DRP were involved in the interventions. All of the health education initiatives we've created have been welcomed and adopted by the patients. Many actual and potential DRP remained unresolved or not stopped from doing so. The resolution and prevention of these DRPs required modification in the drug regimen which was solely based on a medical decision. Problems with drug therapy addressed and prevented are illustrated in Figure 2 .

This study prevented 350 potential DRPs and resolved 277 actual DRPs. 


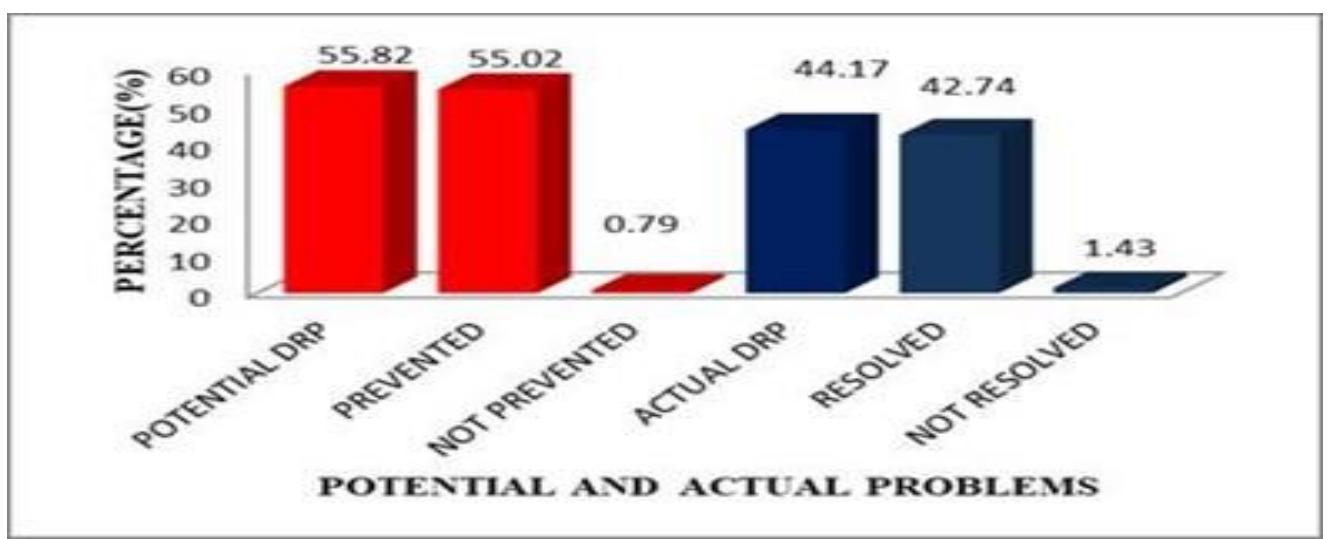

Figure 2: Quantitative distribution of Drug related problems Resolved and Prevented.

Table 2: Problems

\begin{tabular}{|c|r|c|c|}
\hline Code & Problems & Total no. cases & Percentage (\%) \\
\hline P1 & Treatment effectiveness & 171 & 27.27 \\
\hline P1.1 & No effect of drug treatment & 9 & 1.43 \\
\hline P1.2 & Effect of drug treatment not Optimum & 152 & 24.24 \\
\hline P1.3 & Untreated symptoms/indications & 10 & 1.59 \\
\hline P2 & Treatment safety & 57 & 9.09 \\
\hline P2.1 & Adverse drug event (possibly) Occurring & 9.09 \\
\hline P3 & Others & 57 & 63.95 \\
\hline P3.1 & Problem with cost effectiveness of the treatment & 399 & 2 \\
\hline P3.2 & Unnecessary drug treatment & 2 & 0.3 \\
\hline P3.3 & Unclear problem/complaint & 12 & 1.9 \\
\hline
\end{tabular}

\section{Table 3: Causes}

\begin{tabular}{|c|c|c|c|}
\hline Code & Causes & Total No. Cases & Percentage (\%) \\
\hline $\mathrm{C} 1$ & Drug selection & 141 & 22.56 \\
\hline C1.1 & In appropriate drug according to guideline/formulary & 23 & 3.67 \\
\hline C1.2. & Inappropriate drug & 95 & 15.15 \\
\hline C1.3 & No indication of drug & 0 & 0 \\
\hline C1.4 & Inappropriate combination of drug & 0 & 0 \\
\hline C1.5 & Inappropriate duplication of therapeutic group & 10 & 1.59 \\
\hline C1.6 & No drug treatment in spite of existing indication & 9 & 1.43 \\
\hline C1.7 & Too many drugs & 4 & 0.63 \\
\hline $\mathrm{C} 2$ & Drug form & 0 & 0 \\
\hline $\mathrm{C} 2.1$ & Inappropriate drug form & 0 & 0 \\
\hline C3 & Dose selection & 104 & 16.58 \\
\hline C3.1 & Drug dose too low & 4 & 0.63 \\
\hline C3.2 & Drug dose too high & 26 & 4.14 \\
\hline C3.3 & Dosage regimen not frequent enough & 2 & 0.31 \\
\hline $\mathrm{C} 3.4$ & Dosage regimen too frequent & 10 & 1.59 \\
\hline C3.5 & Dose timing instructions wrong, unclear and missing & 62 & 9.88 \\
\hline $\mathrm{C} 4$ & Treatment duration & 1 & 0.159 \\
\hline C4.1 & Duration of treatment too short & 0 & 0 \\
\hline $\mathrm{C} 4.2$ & Duration of treatment too long & 1 & 0.159 \\
\hline $\mathrm{C} 5$ & Dispensing & 39 & 6.22 \\
\hline
\end{tabular}




\begin{tabular}{|c||c|c|c|}
\hline C5.1 & Prescribed drug not available & 3 & 0.47 \\
\hline C5.2 & Necessary information not provided & 33 & 5.26 \\
\hline C5.3 & Wong drug, strength or dosage advised (OTC) & 0 \\
\hline C5.4 & Wrong drug/strength dispensed & 0 & 0.47 \\
\hline C6 & Drug use process & 3 & 4.62 \\
\hline C6.1 & Inappropriate Timing of administration and/or dosing intervals & 0.79 \\
\hline C6.2 & Drug under administered & 29 & 2.55 \\
\hline C6.3 & Drug over administered & 0.79 \\
\hline C6.4 & Drug not administered at all & 16 & 0.159 \\
\hline C6.5 & Wrong drug administered & 5 & 0.31 \\
\hline C6.6 & Drug administered via wrong route & 1 & 0 \\
\hline C7 & Patient related & 2 & 0.159 \\
\hline C7.1 & Patient uses/ takes less drug than prescribed or does not take the drug at all & 0 & 0.159 \\
\hline C7.2 & Patient uses/ takes more drug than prescribed & 1 & 0 \\
\hline C7.3 & Patient abuses drug & 0 & 0 \\
\hline C7.4 & Patient uses unnecessary drug & 0 & 0 \\
\hline C7.5 & Patient takes food that interacts & 0 & \\
\hline C7.6 & Patient stores drug inappropriately & 0 & 0 \\
\hline
\end{tabular}

Table 4: Planned Interventions.

\begin{tabular}{|c|c|c|c|}
\hline Code & Planned Interventions & Total No. Cases & Percentage (\%) \\
\hline 11 & At prescriber level & 293 & 46.73 \\
\hline $\mid 1.1$ & Prescriber informed only & 77 & 12.28 \\
\hline 11.2 & Prescriber asked for information & 6 & 0.95 \\
\hline $\mid 1.3$ & Information proposed to prescriber & 138 & 22 \\
\hline I1.4 & Intervention discussed with prescriber & 72 & 11.48 \\
\hline 12 & At patient level & 320 & 51.03 \\
\hline 12.1 & Patient (drug) counseling & 288 & 45.93 \\
\hline 12.2 & Written information provided & 12 & 1.91 \\
\hline 12.3 & Patient referred to the prescriber & 0 & 0 \\
\hline 12.4 & Spoken to family member & 20 & 3.18 \\
\hline 13 & At drug level & 57 & 9.09 \\
\hline 13.1 & Drug changed to & 15 & 2.39 \\
\hline 12.4 & Spoken to family member & 20 & 3.18 \\
\hline 13 & At drug level & 57 & 9.09 \\
\hline 13.1 & Drug changed to & 15 & 2.39 \\
\hline 13.2 & Dosage changed to & 2 & 0.31 \\
\hline 13.3 & Formulation changed to & 0 & 0 \\
\hline 13.4 & Instructions for use changed to & 2 & 0.31 \\
\hline 13.5 & Drug stopped & 35 & 5.58 \\
\hline 13.6 & New drug started & 3 & 0.47 \\
\hline 14 & Other intervention/ activity & 26 & 4.14 \\
\hline 14.1 & Other intervention (specify) & 6 & 0.96 \\
\hline 14.2 & Side effects reported to authorities & 20 & 3.18 \\
\hline
\end{tabular}


Table 5: Acceptance of DRP

\begin{tabular}{|c|c|c|c|}
\hline Code & Implementation & Total No. Of Cases (N=627) & Percentage (\%) \\
\hline A1 & Intervention accepted & 610 & 97.28 \\
\hline A1.1 & Intervention accepted and fully implemented & 271 & 43.22 \\
\hline A1.2 & Intervention accepted partially & 23 & 3.66 \\
\hline A1.3 & Implemented Intervention accepted, but not & 0.31 \\
\hline A1.4 & Implemented Intervention accepted, Implementation & 2 & 50.07 \\
\hline A2 & unknown & 314 & 1.91 \\
\hline A2.1 & Intervention not accepted & 12 & 0 \\
\hline A2.2 & Intervention not accepted; not feasible & 0 & 0 \\
\hline
\end{tabular}

Table 6: Status of DRP

\begin{tabular}{|c|c|c|c|}
\hline Code & Outcome of The Interventions & Total No. of Cases( $\mathrm{N}=627)$ & Percentage (\%) \\
\hline $\mathrm{OO}$ & Not known & 13 & 2.07 \\
\hline 00.1 & Problems status unknown & 13 & 2.07 \\
\hline 01 & Solved & 280 & 44.65 \\
\hline 01.1 & Problem totally solved & 280 & 44.65 \\
\hline $\mathrm{O} 2$ & Partially solved & 320 & 51.03 \\
\hline $\mathrm{O} 2.1$ & Problem partially solved & 320 & 51.03 \\
\hline $\mathrm{O3}$ & Not solved & 14 & 2.23 \\
\hline O3.1 & Problem not solved, lack of cooperation of patient & 2 & 0.31 \\
\hline 03.2 & Problem not solved, lack of cooperation of prescriber & 9 & 1.43 \\
\hline 03.3 & Problem not solved, intervention not effective & 3 & 0.47 \\
\hline 03.4 & No need or possibility to solve the problem & 0 & 0 \\
\hline
\end{tabular}

\section{CONCLUSION}

The overall observation through this study was that by systematically implementing the pharmaceutical care process, the clinical pharmacist has a greater responsibility in preventing and minimizing drug related problems. This may potentially reduce the unnecessary hospital stay, readmission, laboratory monitoring and drug expenditure on drugs.

Acknowledgement: We thank Principal Nandha College of Pharmacy, Dr. J. Balavenkata subramanian (Senior Consultant Anaesthesiologist), Clinical pharmacist and Nurses of Ganga Medical Centre, Coimbatore for administrative and academic support

\section{Abbreviations}

PCNE: Pharmaceutical Care Network Europe; DRP: Drug Related Problem.

\section{Summary}

The present study was conducted to assess the effect of pharmaceutical care service on the identification and resolution of Drug Related Problems in a major trauma care centre. Drug related problems can be minimized by educating the physicians, nurses and other healthcare professionals on appropriate reporting of medication errors, monitoring of adverse reactions, drug interactions etc. The study highlights a potential opportunity in the pharmaceutical care process for the clinical pharmacist.

\section{REFERENCES}

1. Hepler CD, Strand LM. Opportunities and responsibilities in pharmaceutical care. American Journal of Hospital pharmacy 47(3), 1990, 533-543.

2. Cipolle R, Strand L, Peter M. Pharmaceutical care. $2^{\text {nd }}$ edition. New York,NY:Mc Graw-Hill;(1998)

3. Bernd Meibohm, William E. Clinical pharmacodynamics and pharmacokinetics. Atextbook of therapeutics. Richard A Helms, David J Quan, Eric T Herfindal, Dick R Gourleyeds. $8^{\text {th }}$ ed; $10-12$.

4. Viktilkk,Blix HS. The Impact of Clinical Pharmacists on Drug Related Problems and Clinical Outcomes. Clinical pharmacology and Toxicology 102(3), 2008 March, 275-280

5. Blix HS, Viktil KK, Reikvam A, Moger TA, Hjemaas BJ, Pretsch $P$. The majority of hospitalized patients have drug related problems; results from prospective study in general hospitals. European Journal of Clinical Pharmacology 60, 2004, 651-658. 
6. Blix HS, Vitktil KK, Reikvam A, Moger TA. Characteristics of drug related problems discussed by hospital pharmacists in multidisciplinary teams. Pharm World Sci 28(3), 2006, 152-8.

7. Kucukarslan SN, Peters M, Mlynarek M, Nafziger DA. Do pharmacist's presences on rounding teams reduce preventable adverse drug events in hospital general medical units? CMAJ, 170(3), 2004 Feb, 333.
8. Adrienne J Lindblad and Jason Howorko. Integration of a pharmacist into a stroke prevention clinic team. JCPH, 61, 2008, 431.

9. Pharmaceutical Care Network Europe Foundation. PCNE classification for drug related problems version 02, 2017.

Source of Support: None declared.

Conflict of Interest: None declared.

For any question relates to this article, please reach us at: editor@globalresearchonline.net New manuscripts for publication can be submitted at: submit@globalresearchonline.net and submit_ijpsrr@rediffmail.com 